\title{
Wakefield computations for the LCLS Injector (Part I)
}

\author{
June $13^{\text {th }} 2005$ \\ (reedited May 2007) \\ C.Limborg-Deprey, K.Bane
}

\begin{abstract}
In this document, we report on basic wakefield computations used to establish the impedance budget for the LCLS injector. Systematic comparisons between analytic formulae and results from ABCI are done. Finally, a comparison between 2D and 3D wakefield calculations are given for a cross. The three parts of the document are presented as follows:

1- ABCI computations for a few structures (Flange, Bellows ...)

2- Comparison analytic with ABCI runs

3- Comparison Cross and Cavity using MAFIA
\end{abstract}

Part 1: ABCI computations for a few structures (Flange, Bellows ...)

The structures computed correspond to first drawings provided by M.Palrang. Dimensions are given in $\mathrm{mm}$. We studied the evolution of the loss parameters vs rms bunch length. ABCI uses Gaussian bunches. The high frequency content of the standard LCLS pulse (10ps flat top with a rise/fall time of $\sim 1 \mathrm{ps}$ ) is well studied with a Gaussian bunch with an rms of $0.25 \mathrm{~mm}(\sim 0.8 p s)$. For this reason, we studied the three cases of Gaussian pulses with rms length of $0.25 \mathrm{~mm}, 0.5 \mathrm{~mm}$ and $1 \mathrm{~mm}$.

Four types of geometry were studied: flanges, steps , welded bellows, creneau bellows.

\footnotetext{
${ }^{*}$ Work supported in part by the DOE Contract DE-AC02-76SF00515.

This work was performed in support of the LCLS project at SLAC.
} 


\subsection{Flange:}

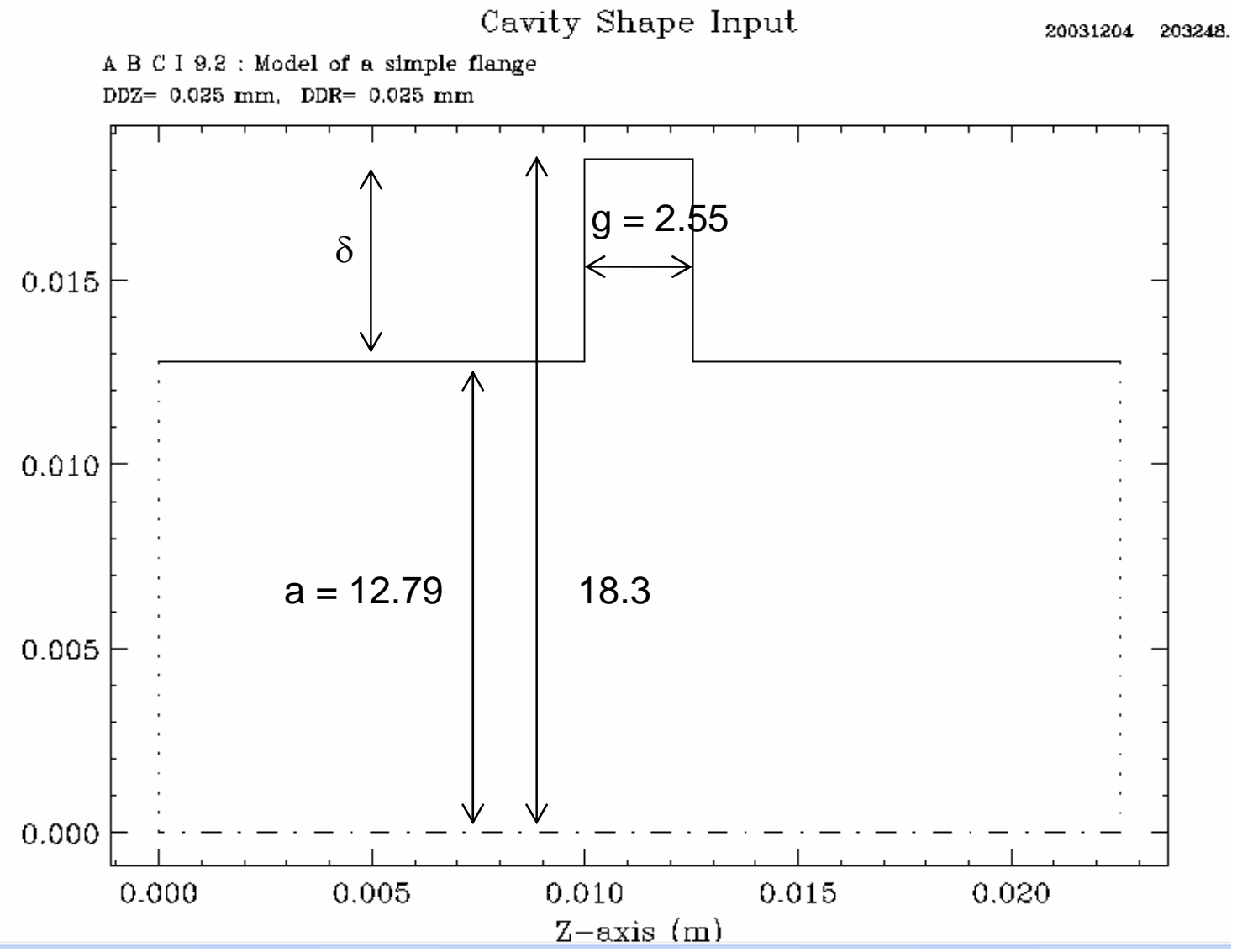

Transverse

\begin{tabular}{|l|l|l|}
\hline$\sigma(\mathrm{mm})$ & $\mathrm{Max}(\mathrm{V} / \mathrm{pC} / \mathrm{m})$ & $\mathrm{k}(\mathrm{V} / \mathrm{pC} / \mathrm{m})$ \\
\hline 1 & 30.6 & 9.04 \\
\hline 0.5 & 31.8 & 6.97 \\
\hline 0.25 & 24.9 & 5.22 \\
\hline
\end{tabular}

Longitudinal

\begin{tabular}{|l|l|l|}
\hline$\sigma(\mathrm{mm})$ & Min $(\mathrm{V} / \mathrm{pC})$ & $\mathrm{k}(\mathrm{V} / \mathrm{pC})$ \\
\hline 1 & 0.72 & 0.521 \\
\hline 0.5 & 1.13 & 0.811 \\
\hline 0.25 & 1.72 & 1.22 \\
\hline
\end{tabular}


$\frac{121}{4}$

Stanford Linear Accelerator Center

Stanford Synchrotron Radiation Laboratory 


\section{2- Flange Gun Out:}

This flange at the gun exit only differs very slightly in dimensions to the standard flange geometry.

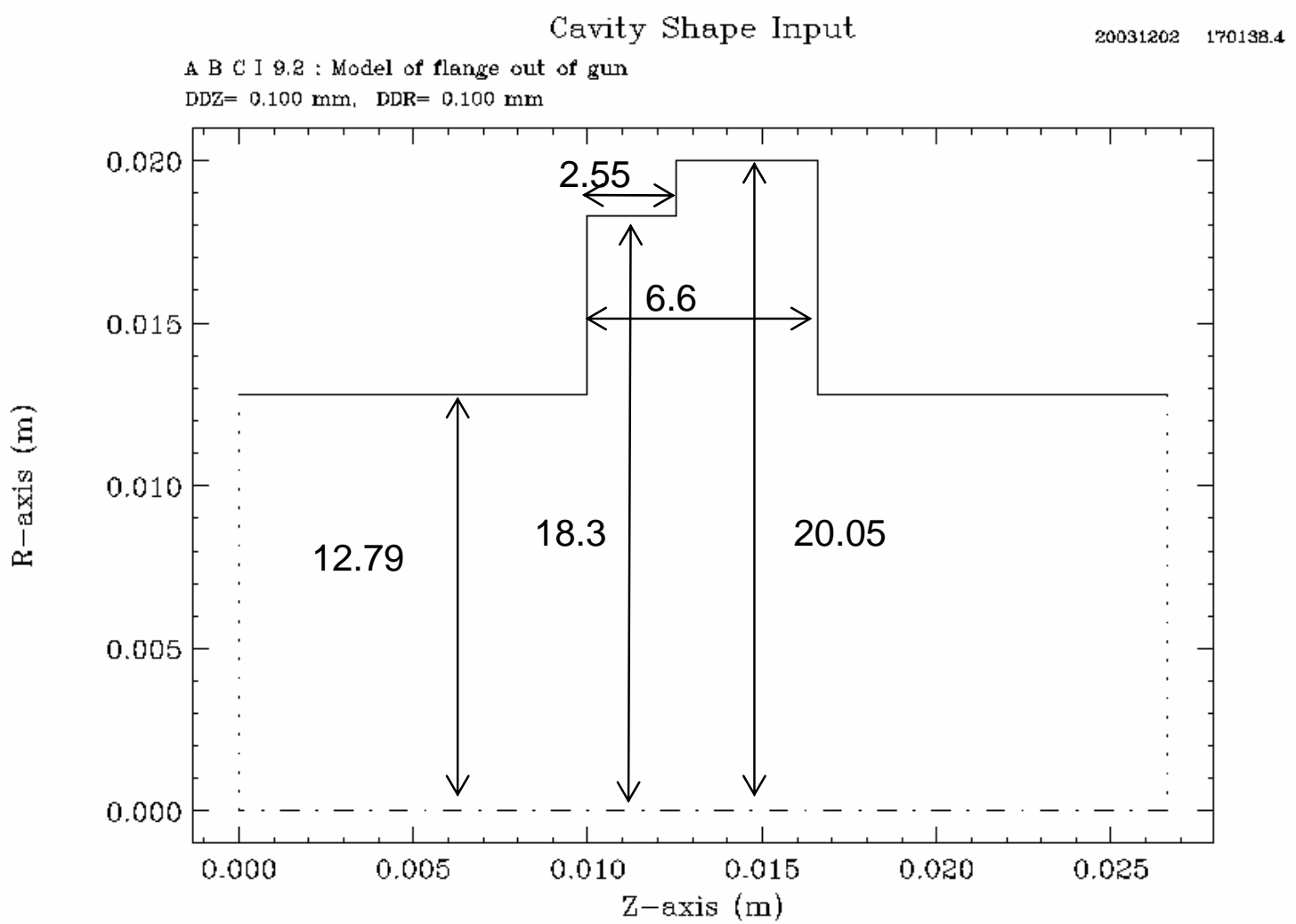

The entrance/exit pipes have the same radius (as a simplification of the structure given by M.Palrang)

Transverse

\begin{tabular}{|l|l|l|}
\hline$\sigma(\mathrm{mm})$ & $\operatorname{Max}(\mathrm{V} / \mathrm{pC} / \mathrm{m})$ & $\mathrm{k}(\mathrm{V} / \mathrm{pC} / \mathrm{m})$ \\
\hline 1 & 60.9 & 15.97 \\
\hline 0.5 & 61.6 & 11.98 \\
\hline
\end{tabular}

Longitudinal

\begin{tabular}{|l|l|l|}
\hline$\sigma(\mathrm{mm})$ & Min $(\mathrm{V} / \mathrm{pC})$ & $\mathrm{k}(\mathrm{V} / \mathrm{pC})$ \\
\hline 1 & 1.32 & 0.83 \\
\hline 0.5 & 2.0 & 1.43 \\
\hline
\end{tabular}




\section{1-3: Welded Bellows :}

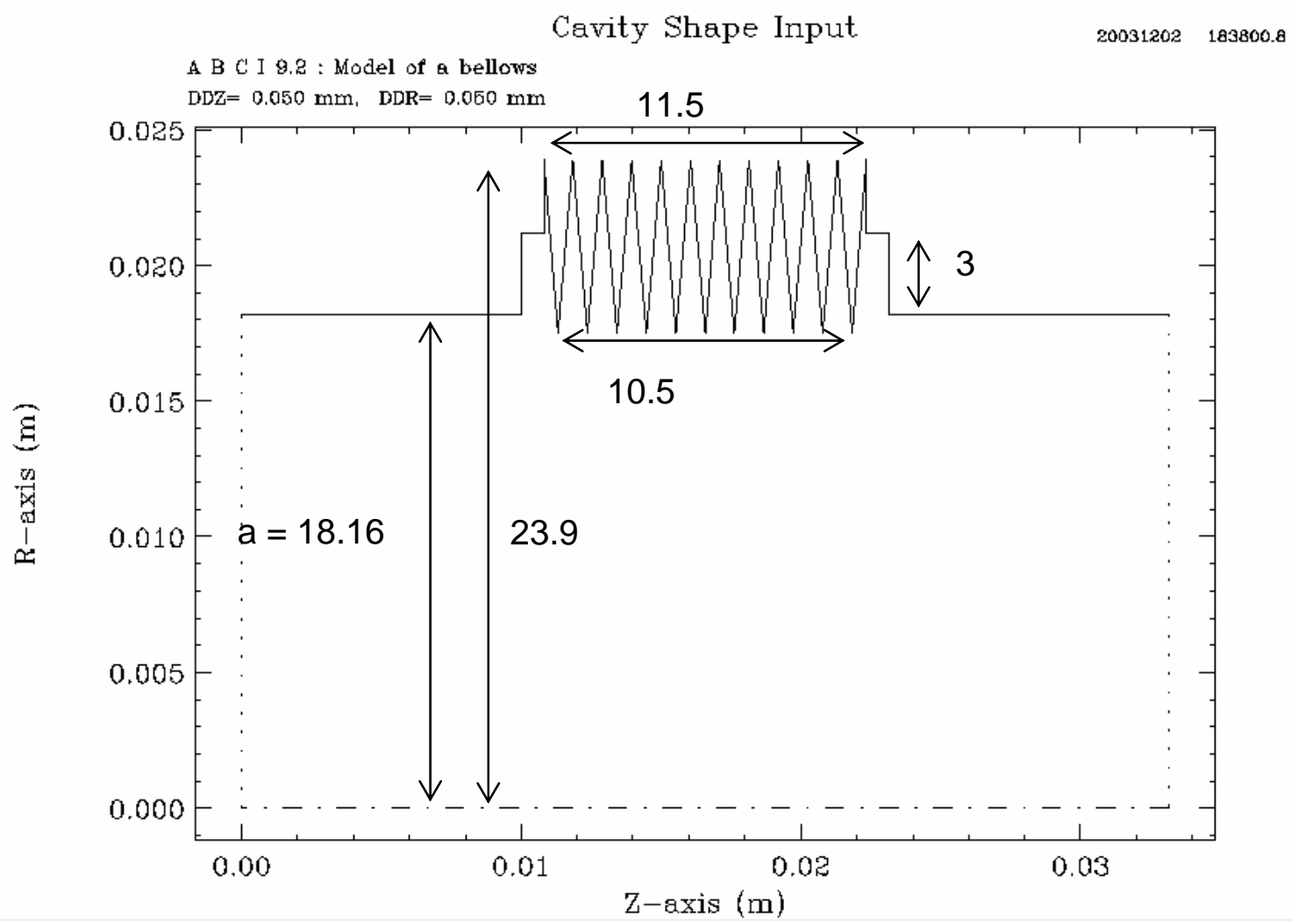

With pipe radius a $=18.16 \mathrm{~mm}$

Transverse

\begin{tabular}{|l|l|l|}
\hline$\sigma(\mathrm{mm})$ & $\operatorname{Max}(\mathrm{V} / \mathrm{pC} / \mathrm{m})$ & $\mathrm{k}(\mathrm{V} / \mathrm{pC} / \mathrm{m})$ \\
\hline 1 & 36 & 12.7 \\
\hline 0.5 & 39.8 & 11.33 \\
\hline 0.25 & 41.2 & 9.479 \\
\hline
\end{tabular}

Longitudinal

\begin{tabular}{|l|l|l|}
\hline$\sigma(\mathrm{mm})$ & Min $(\mathrm{V} / \mathrm{pC})$ & $\mathrm{k}(\mathrm{V} / \mathrm{pC})$ \\
\hline 1 & 2.0 & 1.44 \\
\hline 0.5 & 3.52 & 2.56 \\
\hline 0.25 & 5.71 & 4.21 \\
\hline
\end{tabular}

With pipe radius $=12.7 \mathrm{~mm}$

Transverse

\begin{tabular}{|l|l|l|}
\hline$\sigma(\mathrm{mm})$ & $\operatorname{Max}(\mathrm{V} / \mathrm{pC} / \mathrm{m})$ & $\mathrm{k}(\mathrm{V} / \mathrm{pC} / \mathrm{m})$ \\
\hline 1 & 103.7 & 36.9 \\
\hline 0.5 & 114.8 & 32.88 \\
\hline 0.25 & 119 & 27.9 \\
\hline
\end{tabular}


Longitudinal

\begin{tabular}{|l|l|l|}
\hline$\sigma(\mathrm{mm})$ & $\operatorname{Min}(\mathrm{V} / \mathrm{pC})$ & $\mathrm{k}(\mathrm{V} / \mathrm{pC})$ \\
\hline 1 & 2.9 & 2.07 \\
\hline 0.5 & 5 & 3.69 \\
\hline 0.25 & 8.3 & 6.13 \\
\hline
\end{tabular}

\section{1-4 Creneau Bellows :}

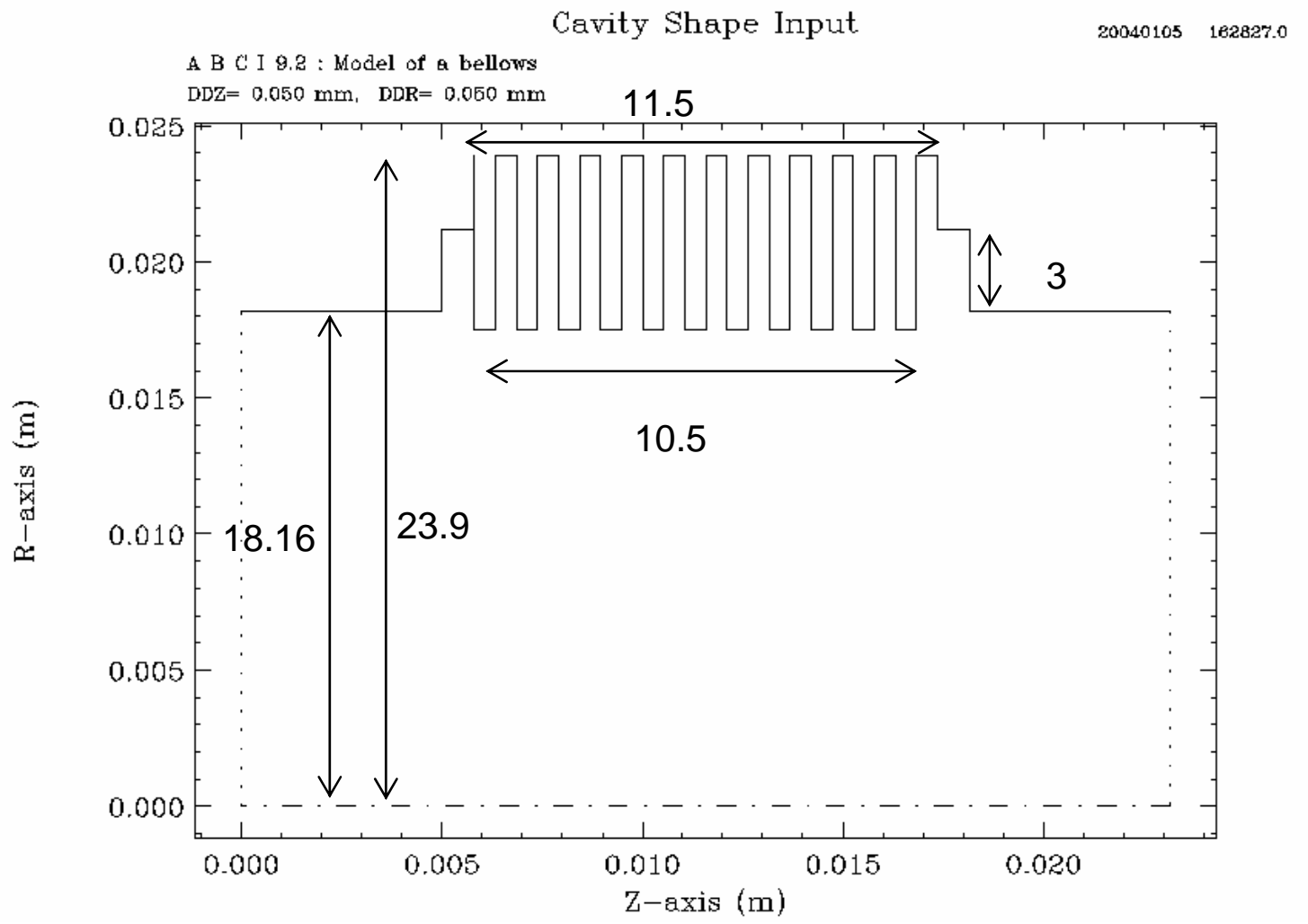

With radius a $=18.7$

Transverse

\begin{tabular}{|l|l|l|}
\hline$\sigma(\mathrm{mm})$ & $\operatorname{Max}(\mathrm{V} / \mathrm{pC} / \mathrm{m})$ & $\mathrm{k}(\mathrm{V} / \mathrm{pC} / \mathrm{m})$ \\
\hline 1 & 59 & 19 \\
\hline 0.5 & 58 & 14.6 \\
\hline 0.25 & & \\
\hline
\end{tabular}

Longitudinal

\begin{tabular}{|l|l|l|}
\hline$\sigma(\mathrm{mm})$ & Min $(\mathrm{V} / \mathrm{pC})$ & $\mathrm{k}(\mathrm{V} / \mathrm{pC})$ \\
\hline 1 & 2.91 & 2.11 \\
\hline 0.5 & 4.45 & 3.27 \\
\hline 0.25 & & \\
\hline
\end{tabular}

With radius a $=12.7 \mathrm{~mm}$

Transverse 


\begin{tabular}{|l|l|l|}
\hline$\sigma(\mathrm{mm})$ & $\operatorname{Max}(\mathrm{V} / \mathrm{pC} / \mathrm{m})$ & $\mathrm{k}(\mathrm{V} / \mathrm{pC} / \mathrm{m})$ \\
\hline 1 & 174 & 56.8 \\
\hline 0.5 & 169 & 43.1 \\
\hline 0.25 & 170 & 34.46 \\
\hline
\end{tabular}

Longitudinal

\begin{tabular}{|l|l|l|}
\hline$\sigma(\mathrm{mm})$ & Min $(\mathrm{V} / \mathrm{pC})$ & $\mathrm{k}(\mathrm{V} / \mathrm{pC})$ \\
\hline 1 & 4.24 & 3.08 \\
\hline 0.5 & 6.46 & 4.75 \\
\hline 0.25 & 10.0 & 7.46 \\
\hline
\end{tabular}

\section{5 - Interpretation and comments:}

A transverse wakefield of $20 \mathrm{~V} / \mathrm{pC} / \mathrm{m}$ from head-to-tail will produces $\Delta \mathrm{px}=2 \mathrm{~V} / \mathrm{nC}$ for a $100 \mu \mathrm{m}$ transverse beam offset.

So a kick of $\theta=0.4 \mu \mathrm{rad}$ at $5 \mathrm{MeV}$

The growth in emittance is given by $\theta / \sqrt{ } \gamma_{t} \varepsilon$.

$\sqrt{ } \gamma_{t} \varepsilon$ can vary between $100 \mu \mathrm{rad}$ and $3000 \mu$ rad in the GTL section.

For an offset of $1 \mathrm{~mm}$, we would get an emittance growth which varies between $0.0133 \%$ and $4 \%$ depending on the location of the source wakefield. More details are given in Part 2 .

\section{6 - Conclusion:}

A more accurate computation is required using local values of betatron functions and wakefields. The wakefield extracted from ABCI is computed from a Gaussian bunch. To do the convolution accurately, one needs to compute the Green's function and to use the electron bunch longitudinal profile (ideally flat top with fast rise/fall times).

Before we use the Green's function, we compared its accuracy with ABCI results for a case of a Gaussian bunch. 


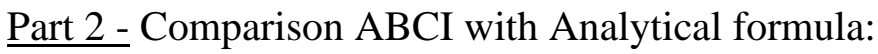

\section{2-1 Flange:}

For a flange, the diffraction formula [1] is used.

kloss $=4.34 \frac{Z_{o} c}{\pi^{3} a^{3}} \sqrt{g \sigma_{z}}$ in $\mathrm{V} / \mathrm{pC} / \mathrm{m}$

\begin{tabular}{|l|l|l|l|l|l|}
\hline$\sigma[\mathrm{mm}]$ & $a[\mathrm{~mm}]$ & $\delta[\mathrm{mm}]$ & $g[\mathrm{~mm}]$ & $k_{\text {loss }} A B C I$ & $k_{\text {loss }}$ theory \\
\hline 1 & 10 & 5 & 1 & 10.5 & 15.8 \\
\hline 1 & 10 & $\mathbf{1 5}$ & 1 & 10.5 & 15.8 \\
\hline 1 & 10 & 5 & $\mathbf{1 0}$ & 41.89 & 50.0 \\
\hline $\mathbf{2}$ & 10 & 5 & 1 & 11.98 & 22.3 \\
\hline $\mathbf{0 . 5}$ & 10 & 5 & 1 & 8.36 & 11.18 \\
\hline
\end{tabular}

Table 2.1 - Evolution of kloss with gap , step length, bunch length

The formula gets more accurate for longer gaps or smaller bunch (for large g/ $\sigma$ ratio)

\section{2-2 Bellows:}

For a single mode, the wave number is $k=\frac{2}{\sqrt{a \delta}}$

The wake function for a that mode is then given by $W_{x}=W_{x o} \sin (k s)$

The transverse amplitude of the wakefield per unit length is $W_{x o}=\frac{2 Z_{o} c}{a^{4} k}$ in V/pC/m

The voltage induced is then given by $\operatorname{Vind}(s)=\int_{s p=0}^{s p=\infty} \frac{1}{\sqrt{2 \pi} \sigma} e^{-\frac{(s-s p)^{2}}{2 \sigma^{2}}} W_{x}(s p) d s p$

The first moment of the loss parameter is given by $k_{\text {loss }, 1}=\int_{s=-\infty}^{s=\infty} \frac{1}{\sqrt{2 \pi} \sigma} e^{-\frac{s^{2}}{2 \sigma^{2}}} V_{\text {ind }}(s) d s$

The kloss for a Gaussian bunch can then be computed analytically using Mathematica (notebook from K.Bane).

Comparison with ABCI :

\begin{tabular}{|l|l|l|l|l|l|}
\hline$\sigma[\mathrm{mm}]$ & $a[\mathrm{~mm}]$ & $\delta[\mathrm{mm}]$ & & $k_{\text {loss }} A B C I$ & $k_{\text {loss }}$ theory \\
\hline $\mathbf{1}$ & 12.7 & 3 & & 165.3 & 191.7 \\
\hline $\mathbf{1}$ & 16 & 3 & 78.2 & 75.5 \\
\hline $\mathbf{1}$ & 16 & 6 & 78.2 & 77.7 \\
\hline
\end{tabular}

Table 2-2 Comparison analytical formula and ABCI for bellows geometry 
Part 3: Comparison cross and cavity using Mafia

We first checked on simple examples similar to those of paragraph 1, that ABCI and Mafia were giving the same results for cylindrical symmetry structures g 1.5 mm.

We then computed transverse wakefields for a cross and a cavity.

The two structures have geometry shown in the figures below

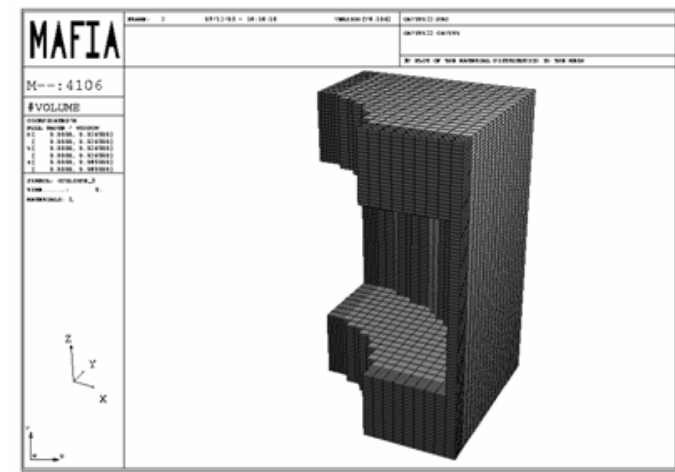

Cavity

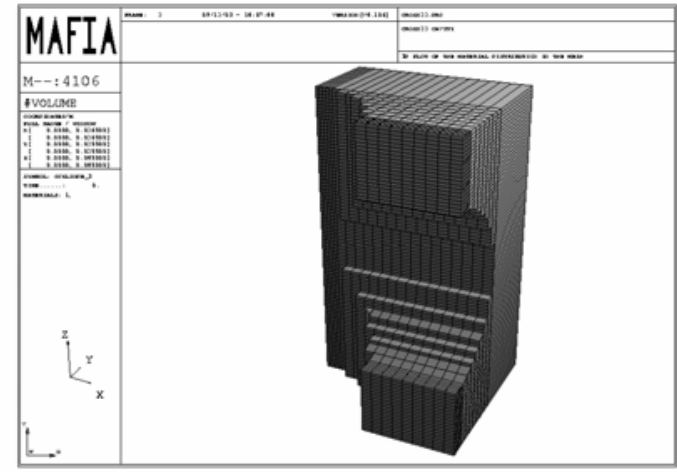

Cross

\begin{tabular}{l|lll|lll}
\hline$\sigma[\mathrm{mm}]$ & $\mathrm{g}[\mathrm{mm}]$ & $\mathrm{a}[\mathrm{mm}]$ & $\delta[\mathrm{mm}]$ & $\begin{array}{l}\mathrm{k}_{\text {loss }} \text { cross } \\
\text { (MAFIA) }\end{array}$ & $\begin{array}{l}\mathrm{k}_{\text {loss }} \text { cavity } \\
\text { (MAFIA) }\end{array}$ & $\begin{array}{l}\mathrm{k}_{\text {loss }} \text { cavity } \\
(\text { ABCI) }\end{array}$ \\
\hline $\mathbf{1}$ & 25.4 & 12.7 & 12.3 & 20.9 & 26.5 & 34 \\
$\mathbf{1}$ & 5 & 12.7 & 12.3 & & 11.2 & 14 \\
\hline 1 & 1.5 & 12.7 & 9 & & 5.92 & 6.76 \\
\hline
\end{tabular}

The agreement between ABCI and MAFIA for cylindrical symmetry structure was better for narrower cavities (flanges). A 2D MAFIA computation will be done too.

The maximum of the wakefield amplitude is very close $(<10 \%)$ for MAFIA and ABCI.

The loss parameter is larger for a cavity than for a cross. The 2D computations give an overestimate. In the future we will assimilate crosses to cavities knowing that we treat the most pessimistic case.

\section{References:}

[1] "Wakefields of Very Short Bunches in an Accelerating Cavity”, K.Bane and Matthew Sands, SLAC-PUB-4441 